\title{
Research in Teaching and Teacher Education: qualitative methods and grounded theory methodology
}

RONALD G. SULTANA, The University of Malta

This article critically appraises the advantages and disadvantages of qualitative methods for the collection of data in the fields of teaching and teacher education. Strategies are suggested to improve ethnographies, and the issue of normative as against positivist approaches to knowledge is addressed. Glaser \& Strauss' 'grounded theory' methodology is then presented as tool for the collection, organisation and analysis of qualitative data, and for the generation of substantive and formal theories about education.

\section{The Value of Qualitative Methodology}

Educational researchers increasingly have become attracted by a qualitative methodology in collecting data. Rist (1984), for instance, notes that in the past decade there has been a dissolution of the natural science model of inquiry as the pre-eminent model in policy studies related to education. What in the past often has been acknowledged as "the only available route to cumulative progress" (Campbell \& Stanley, 1963), namely, the 'scientific' approach represented by research strategies involving collecting and analysing quantitive data, has been found wanting in a number of important areas. Quantitative approaches therefore have not provided data which addressed many of the most pressing issues; nor have they respected the fluidity and change in social environments or examined processes as against outcomes (Rist, 1984).

Shipman (1984), in a paper on ethnography and public policy, describes policymakers as "hungry for evidence" and he regards ethnographic work as having a clear potential role by virtue of the inadequacies of previous work. He says:

Much of the justification for ethnographic approaches to research comes from the failures of the positivists to deliver evidence on which policymakers, including teachers in their classrooms, could depend. (Shipman, 1984, p. 12)

There has been a growing realisation that statistical realities do not necessarily coincide with cultural realities. As a research strategy, quantitative methodologies on their own have failed to be sufficiently flexible and open-ended to accommodate the ever-present serendipitous aspect of human behaviour, and therefore could reflect only on that which stood long enough to be measured in conventional ways. The irony of this is that these static aspects of the environment are often the least interesting, the least critical and the least amenable to change (Bronfenbrenner, 1979).

On the other hand, by an immersion in a social situation, a researcher using qualitative methodology has a unique opportunity to gain a first-hand understanding of social 'realities', involved as he/she is in describing and analysing values, behaviours, settings and interactions of participants. Such a description and analysis moreover 
could trace these values, behaviours and interactions over a period of time. Asking the question, 'What is going on here?' is at once disarmingly simple and incredibly complex. In trying to answer this question by immersion in the field, ethnography leaves the participant observer most open to the unanticipated discovery of triangulating chance emergence of data (Webb et al., 1966). In contrast, the rigidity of survey and experimental designs unaided by a strong qualitative component explicitly seek to allow maximum researcher control, while leaving subjects more free to dissimulate as they are removed from their everyday constraints (Becker, 1970).

Qualitative methodology, however, has its weaknesses as well as its strengths. Hargreaves (1981), for instance, criticises the sociology of education for producing too much atheoretical empirical work, often ethnographic, which is perhaps grafted onto fashionable theoretical perspectives but which does not represent a form of rigorous testing of theory by which the discipline might be developed. Delamont (1981) suggests that ethnography has been blinkered and parochial, failing to draw on comparative studies of different cultures and on studies of different substantive areas. In her opinion, it also has failed to be sufficiently analytical and theoretical. Woods (1984) distinguishes two phases in the development of ethnographic work, the first of which is largely descriptive, with a priority on providing empirically grounded and valid accounts of the perspectives of actors in the settings studied. The second, and more promising phase according to Woods, generates projects which:

... use existing ethnographic studies as a launching pad, (are) theoretically conscious in the early stage, and engage in theoretical sampling, hypothesis information and testing. (Woods, 1984, p. 14)

Pollard (1984), moreover, refers to the three classic areas of reliability, validity and generalisability. The individualistic nature of ethnographic research always has made the question of reliability an awkward one, and the question of generalisability is challenging given a case study base, where the ethnography is idiosyncratic to the time of investigation, and its findings might relate only to the group under investigation (Ramsay, 1985).

\section{Towards a Refinement of Qualitative Methodology}

Chelimsky (1983) argues that qualitative research can be improved and its effect on policy-making enhanced if adequate attention is given to what he calls "technical adequacy". This includes a number of factors, the most important of which would be the absence of major conceptual errors, the correct application of technical procedures, and the drawing of conclusions and inferences based on actual data.

The importance of these factors in ensuring the "technical adequacy" of qualitative research becomes evident in a consideration of one of the best-known ethnographiesthat of Willis (1977) -and of criticisms that have been levelled at it during the decade following its publication. Thus, by focusing on Willis' work and criticisms of it as made by, inter alia, Fine (1979), Atkinson (1979; quoted in Gordon West, 1984), Gordon West (1984) and Walker (1986), the researcher can avoid the same pitfalls that these authors highlighted and come closer to a rigorous application of methodology as set out in standard textbooks on ethnography (such as Glaser \& Strauss, 1967; Becker, 1970; Bogdan \& Taylor, 1975). Attention therefore should be given to:

1. describing entry into the field;

2. describing the researcher's expectations and presuppositions at the time; 
3. analysing the biasing commitments which were involved;

4. describing the surprises that were encountered;

5. enhancing external validity of the research by utilising comparative sampling;

6. avoiding Willis' sole focus on class, in considering the experience of being female, or a member of an ethnic minority or both;

7. reconciling the micro/macro, liberty/determinism, functional requisite/action dilemma which remains ambiguously unstated in Willis;

8. generating categories from data. In Willis' case, it is never very clear whether his categories of "penetrations", "limitations", "confirmations" and "dislocations" are derived from a priori deductive structuralist theorising about production and reproduction of ideology, or the $a$ posteriori inductive grounded theory of Glaser \& Strauss (1967). Atkinson (1979) in fact notes that, without a closer articulation of the ethnograpy and the analysis, "Learning to Labour" remains open to the charge of having 'spot-welded' a Marxist analysis together with its descriptive material. Ramsay (1983) makes similar comments with reference to Anyon's (1981) ethnographic work, arguing that:

...social life is not as predictable as Anyon presents it, and we conjecture about the possibility of an operative mirror effect. Perhaps her research tells us as much about the researcher's predispositions as about the phenomenon. (Ramsay, 1983, p. 296)

9. displaying the process of analysis as explicitly as possible, so that the conceptualisation can be more open to evaluation and possible revision.

\section{Convergent Methodology}

Another way of improving qualitative methodology is by a judicious use of strategies from the quantitative field. In the past, there has been a rigid dichotomy set up between the two approaches to data collection. However, the fact that "statistical data can often lead to mathematically correct but socially ludicrous conclusions" (Sieber, 1973) does not necessarily mean that surveys and quantitative data cannot exist together with qualitative data in a relationship where there is a mutual contribution. This is sometimes desirable, or even necessary, for the verification of field interpretation (Webb et al., 1966), for the casting of new light on field observations and for the demonstration of the generalisability of a single observation. Thus, when an observation plays an important role in the theoretical structure of fieldwork, survey data becomes essential for buttressing the argument. Trow (1957) in fact retorted quite sharply when Becker \& Geer (1957) asserted the superiority of qualitative strategies, such as participant observation, over quantitative ones:

Let us be done with the arguments of 'participant observation' versus interviewing-as we have largely dispensed with the arguments for psychology versus sociology-and get on with the business of attacking our problems with the widest array of conceptual and methodological tools that we possess and they demand. This does not preclude discussion and debate regarding the relative usefulness of different methods for the study of specific problems or types of problems. (Trow, 1957, p. 35)

Not only can qualitative data provide an important "validity check" on statistical data 
(Rist, 1984), but research in itself will advance more rapidly through increased use of multiple research designs and multiple lines of evidence than through any forseeable technical improvements in design and analysis (Lipsey et al., 1984). Convergence or agreement between methods enhances the belief that the results are valid and not a methodological artifact (Bouchard, 1976).

Convergent methodology, however, has some fundamental philosophical questions to resolve. In tracing the transition from conflict to détente to cooperation between qualitative and quantitative inquiry, Smith \& Heshusius (1986) rightly have pointed out that compatibility is often based on a confusion over two different definitions of method. Thus, researchers often mirror criteria like 'validity', seemingly forgetting that there are very different and contradictory assumptions about the nature of knowledge being made in the two approaches:

The phrases "research has shown..." and "the results of research indicate ..." are subject to different interpretations, given different paradigms. For quantitative inquiry, these phrases are claims to an accurate reflection of reality or the claim of certitude that one has discovered how some bit of the social or educational world really is. For qualitative inquiry, these phrases announce an interpretation that, to the extent that it finds agreement, becomes reality for those people as it is at any given time and place. The former expresses certitude; the latter presents a description constrained by values and interests to be compared with other descriptions constrained by other values and interests. (Smith \& Heshusius, 1986, p. 10-11)

Qualitative research therefore at best can claim to provide people involved in similar circumstances with material which could be of some use to them in sharpening their own perceptions and procedures, rather than to produce some set of 'universal truths'. Qualitative techniques such as observation and informal interviewing of different participants in the field moreover are admirably suited to the achievement of competitive definitions of situations and meanings.

\section{The Normative Nature of Qualitative Research}

It is important at this point to highlight the normative-as opposed to the positivistnature of qualitative educational research. In his synthesis of twentieth century philosophical forces dialectically at work in the shaping and challenging of our views of what constitutes social science, Bernstein (1978) argues that good social and political theory must at one and the same time be empirical (grounded in data), interpretive (dealing with human intersubjective and subjective meaning) and normative-critical (bringing operative ideologies to conscious awareness and make action-value decisions). Soltis (1984) applies this analysis to empirical, interpretive and normative inquiry in the educational arena, calling for:

... a comprehensive concept of educational research requiring not just a pluralistic tolerance of different research philosophies, but mutual support, understanding, conversation, and rational critique amongst educational researchers and across traditions. (Soltis, 1985, p. 5)

Theorists like Marcuse and Habermas consider pure positivism as an ideology focusing our inquiries and lives on the technical, and on finding effective means to get us to educational ends that we take for granted-ends that preserve the status quo and the 
power of the dominant class without regard for what kind of social and human life our current forms of schooling produce and reproduce.

Researchers who share Habermas' and Marcuse's rejection of positivism seek to demystify educational institutions and practices. Following the epistemological tradition of the Frankfurt school, normative and interpretative researchers reject the myth of value-free research into educational phenomena, and accordingly stress the need for an inquiry that takes into account the historical-ideological moment which we live in and the influence that it has on us. Researchers working in this mode need to recognise their personal biases which can pose a potential threat to the credibility of an emerging theory. Glaser \& Strauss (1967) argue that field workers cannot possibly erase all predispositions from their mind. Ramsay (1983) suggests that researchers spell out their predispositions prior to the commencement of the research.

Gadamer's (1979) discussion of modern hermeneutics throws light on the dilemma of 'biased' research. According to Gadamer, hermeneutics is characterised by a reflexivity which enables us to understand the possibility of a multiplicity of viewpoints and "to respond to opposing arguments by a reflection which deliberately places us in the perspective of the other" (Gadamer, 1979, p. 110). Researchers (or interpreters of text) do not bracket off the 'prejudices' which they bring with them, and place themselves in the position of the 'others' in order to understand them. Rather, the process of understanding entails a 'fusion' of the 'horizon' or life-world of the researcher with that of the researched and, therefore, there can be no one correct interpretation of that reality. Nor can there be any neutral standpoint from which data can be interpreted. Hence, as has been discussed above, the empiricist conception of objectivity is seen to be an illusion.

Gadamer also correctly points out that the interpreters of texts or of social situations become aware of the structure of their own prejudices: "Only through others do we gain the knowledge of ourselves" (Gadamer, 1979, p. 107). Thus, while the researcher cannot help but filter new data through what Berger \& Luckmann (1971) call the "inner self", this same inner self is revealed for inspection and opened up to challenge by emerging data. This process is also important when it comes to writing out the actual report, for it is quite possible that, given different ideological assumptions, quite different interpretations can be made.

Researcher bias and predispositions are best generally kept privy from the researched during the inquiry because of problems related to "observer effect" (Rose, 1975) or "impression management" (Goffman, 1957). Not only is it possible that people change their behaviour when they are being observed but it is also likely that, if they know the researcher's ideological predispositions, they present behaviours and answers which they think the researcher wants to see and hear.

It is important to be aware of other aspects of research bias which can arise from the gender, class and ethnicity of the researcher. Some feminist researchers have argued that male researchers should not research social situations where feminist issues are involved. James (1986) has argued that gender places limits on sociological investigation in which the gender of the researcher becomes problematic. Thus "gender may determine the matter of access, or become an issue for reasons of sensitivity or propriety" (James, 1986, p. 19). The researcher needs carefully to consider the consequences of gender for sociological inquiry. Frankenberg (1976) and Morgan (1981) are two examples of male sociologists who have examined the effects of their gender on their research practices. The same can be said of other dimensions such as class, ethnicity, age and religious beliefs. 


\section{Grounded Theory Methodology}

One research strategy which realises the potential of qualitative inquiry is Glaser \& Strauss' (1965) grounded theory methodology, which the authors developed in their study on death and dying. It fulfills the requirements described above in that it:

1. develops theory from data and, in particular, qualitative data;

2. enhances validity and generalisability through the procedure of 'constant comparative analysis';

3. provides a vehicle not only for systemising and coordinating data collection, but also for the analysis of that data;

4. enhances the possibility of use of the research in educational policy-making;

5. generates possibilities of educative interaction with staff members and other key people in the running of the school.

In describing the grounded theory strategy, an outline of step by step procedures for analytic generation of theory is presented below.

\section{Step 1}

Starting with a "sensitising concept" (Blumer, 1969) or topic area, the researcher attempts a rough first definition of the phenomenal form to be explained, ideally drawing upon subjects' understanding of key issues or problems in their worlds. Glaser \& Strauss (1967) refer to this within the concept of "theoretical sampling". This is a process of data collection for generating theory, whereby the analyst jointly collects, codes and analyses the data and decides what data to collect next and where to find them, in order to develop the theory as it emerges. Theoretical sampling therefore forces the researcher to consider which groups to observe, when to observe them, when to stop observing them and what data to gather.

In order to initiate theoretical sampling, the researcher can collect preliminary data which provides a foothold from which she/he can proceed to gather further data-by means of questionnaire, interview, observation and document collection-on the problem or issue investigated. Such preliminary data could consist of a literature review, perusal of documents issued by the institution to be studied, as well as the involvement in meetings, unstructured interviews and correspondence with prospective participants. This sort of initial inquiry also could take the form of a 'pilot study', an invaluable strategy in the clarification of research questions and in the definition of the parameters of the research. Of theoretical importance are debriefing sessions with the researcher's supervisors to outline clearly the predispositions with which the researcher enters the field.

\section{Step 2}

The data collected as a result of the initial 'theoretical sampling' is grouped into categories and, if necessary terms are redefined, and indicators are specified. Then, as each category of data begins to emerge, and other data begin to fit that category, properties or sub-themes within that category can be discerned. In turn, hunches or propositions also can be formulated. As with all empirical claims, such propositions must be explicity and logically non-tautologous (i.e. open to empirical refutation). This analysis of data, which Glaser \& Strauss (1967) call "constant comparative 
analysis", provides the researcher with 'leads' for further data collection. Glaser (1978) elaborated on this strategy, noting that, although this constant comparative method can be talked about in terms of a series of steps, what really goes on is circulatory; that is, the analysis keeps doubling back to more data collection and coding until 'theoretical saturation' is reached.

\section{Step 3}

The investigator then returns to the field, collecting more data by deliberately seeking out negative evidence in order to put his or her propositions to the toughest test. This forces modification of the definitions of the forms or their conditions, or reformulations of the forms or their conditions, or reformulations of the hypothesis to account for all cases encountered. This constant comparison of data within and between categories enables categories not only to be verified, but they also become subject to a delimitation process whereby some could be modified or refined, while others perhaps could be merged with more powerful categories. This procedure of contant comparison is repeated conscientiously, with new piece of data being sought until further modification neither occurs nor seems likely.

Qualitative research never really reaches a complete closure stage, but the internal logic and consistency of the analysis and its ability to account for and explain all the data will decide how good an interpretation is (Dobbert, 1982). Glaser \& Strauss (1967, p. 62) refer to this as "theoretical saturation", which is dependent on the researcher's intuition as well as judgement:

Saturation means that no additional data are being found whereby the (researcher) can develop properties of a category. As he sees similar instances over and over again, the researcher becomes empirically confident that a category is saturated. He goes out of his way to look for groups that stretch diversity of data as far as possible, just to make certain that saturation is based on the widest possible range of data on a category... When one category is saturated, nothing remains but to go on to new groups for data on other categories, and attempt to saturate these new categories also.

\section{Step 4}

At the point of saturation, the investigator can choose to write up a relatively limited report on one or a few forms, or can research further the interrelationship of different forms. The write-up concludes a movement from substantive to formal theory (Glaser \& Strauss, 1967), as the researcher leaves 'substantive questions'-or those focused on the particular setting or subjects under study-to tackle 'formal theoretical' ones-or those which build up a theory that could have generalisability beyond the study. The addressing of the latter questions leads to grounded formal theory, which is based on both the data of diverse systematic research, and the substantive theories generated from such data. With the focus on generating formal theory, a comparative analysis is made among different kinds of substantive cases and their theories, which fall within the formal area, without relating the resulting theory back to any one particular area (Glaser, 1978).

Glaser \& Strauss recommend that, in writing grounded theory, data should be 
provided as evidence for conclusions, thus illustrating how the researcher obtained the theory from data. The researcher can achieve this in various ways. He can:

... quote directly from interviews or conversations.... He can include dramatic segments of his on-the-spot field notes. He can quote telling phrases dropped by informants. He can summarise events or persons by constructing readable case studies. $\mathrm{He}$ can try his hand at describing events; and often he will give at least background descriptions of places and spaces. Sometimes he will even offer accounts of personal experience to show how events impinged upon himself. (Glaser \& Strauss, 1967, p.229)

To summarise, a series of strategies has been presented to develop links between theory and research. The researcher first reads through the data that are gathered and gives commonsense impressions in theoretical language. Categories are thus developed, and they are described with data. It is when the data are systematically analysed and constantly compared that a theory results; the theory actually emerges during the very process of doing research. Such an approach emphasises theory generation rather than theory testing, with theories being developed inductively from data as the main task of the researcher. Glaser \& Strauss' methodology has been used successfully by the present author in a major study of New Zealand education systems (Sultana, 1987).

\section{The Impact of Qualitative Research on Teachers and Teacher Education}

A final consideration is the question of impact of the research. It is useful to think in terms of two 'audiences', namely, the teachers involved in the research, and the wider audience including other teachers, policy makers and curriculum planners. Pollard's (1984) opinion is that it is perhaps realistic to expect more impact at the micro level because of the very nature of ethnographic work, and therefore the movement towards "discursive consciousness" (Giddens, 1976) in itself makes an immediate and particular contribution. Being with teachers, talking to teachers, working with teachers-these are essential if a researcher wishes to influence school practices. Such practical action seems to be no less valuable than abstract theorising. Apple (1982) has expressed the view that impacting at the micro level is in itself a correct strategy because of the need to develop counter-hegemonic activity as a social movement in work places such as schools and classrooms.

This tradition of qualitative research also has important implications for the field of teacher education and supervision. Smyth (1989) for instance has pointed out the value of ethnographic "narratives" of what happens in the classroom, and argues that such descriptions are an important starting point for teachers to own and analyse their teaching. Smyth voices the concern of many critical educators when he notes the current trend-reported in a number of educational settings-for a move from a focus on issues of fairness, equality and democratisation to one which emphasises the language of efficiency, standards and productivity. Students-as well as practicising, experienced teachers-become enmeshed in this technocratic rationality, remaining blind to the social implications and context for their activity in the classroom. Smyth $(1989$, p. 24) therefore makes a case for a "critical friend" (who might be a colleague, supervisor, or researcher) to create a:

... written descriptive account of what actually occurs during teaching... [which] provides teachers themselves with an account they can use to 
dialogue and interrogate the critical relationship to the wide cultural and political life that shapes and informs schooling.

This approach to reflexivity follows in the footsteps of culturalist neo-Marxists who are beginning where Gramsci's, Marx's earlier work and Mills' work left off to develop analyses which specifically attempt to link ethnography and history, social structures and individual action. This is in itself a challenge to transform critical insight into praxis. Such research hopefully can give rise to what Gorbutt (1972, p. 7) calls "professional awareness" by "challenging prevailing practices and assumptions in colleges and schools".

Correspondence: Ronald G. Sultana, Faculty of Education, University of Malta, Msida, Malta.

\section{REFERENCES}

ANYon, J. (1981) Social class and school knowledge, Curriculum Inquiry, 11(1), pp. 3-42.

APPLE, M.W. (1982) Education and Power (Boston, Routledge \& Kegan Paul).

BECKER, H.S. (1970) Sociological Method and Substance (Chicago, Aldine).

BeCKer, H.S. \& GeER, B. (1957) Participant observation and interviewing, Human Organisation, 16(3), pp. 28-32.

Berger, P. \& Luckmann, T. (1971) The Social Construction of Reality (Harmondsworth, Penguin).

Bernstein, R.J. (1978) The Restructuring of Social and Political Theory (Pennsylvania, University of Pennsylvania Press).

BLUMER, H. (1969) Symbolic Interactionism (Englewood Cliffs, New York, Prentice-Hall).

Bogdan, R.C. \& TAYLoR, S. (1975) Introduction to Qualitative Research Methods (New York, Wiley).

BouChard, T.J. (1976) Unobtrusive measures: an inventory of uses, Sociology Methods and Research, 4, pp. 267-300.

Bronfendrenner, U. (1979) The Ecology of Human Development (Cambridge, Harvard University Press).

CAmpbell, D.T. \& STANLEY, J.C. (1963) Experimental and Quasi-Experimental Design for Research (Chicago, Rand McNally).

CHELIMSKy, E. (1983) Some thoughts on the nature, definition and measurement of quality in program evaluation, in: R. ST Pierre (Ed.) New Directions in Program Evaluation (San Francisco, Jossey Bass).

DelAmont, S. (1981) All too familiar? A decade in classroom research, Educational Analysis, 3(1), pp. 69-83.

DOBBERT, M.L. (1982) Ethnographic research: theory and application for modern schools and societies (New York, Praeger Publishers).

FIne, B. (1979) The theory and practice of Michel Foucault, Capital and Class, 9, pp. 75-96.

Frankenburg, R. (1976) Sex and gender in British community studies, in: D. BARKER \& S. Allen (Eds.) Sexual dimensions and society: process and change (London, Tavistock).

Gadamer, H.-G. (1979) The problem of historical consciousness, in: P. Rainbow \& W. M. SulLivan (Eds.) Interpretive social science: a reader (Berkeley, University of California Press), pp. 103-160.

GidDENS, A. (1976) New Rules of Sociological Method (London, Hutchinson).

GLASER, B.G. (1978) Theoretical Sensitivity: advances in the Methodology of Grounded Theory (Mill Valley, CA, Sociology Press).

Glaser, B.G. \& STrauss, A.L. (1965) Awareness of Dying (Chicago, Aldine).

GLASER, B.G. \& STRAuss, A.L. (1967) The Discovery of Grounded Theory: strategies for qualitative research (Chicago, Aldine).

GoDDEMS, A. (1976) New Rules of Sociological Method (London, Hutchinson).

Gofrman, E. (1957) The Presentation of Self in Everyday Life (Edinburgh, University of Edinburgh Press). GoRBuTT, D. (1972) The new sociology of education, Education for Teaching, 89(3).

GORDON WEST, W. (1984) Phenomenon and form in interactionist and neo-marxist qualitative educational research, in: L. BARTON \& S. WALKER (Eds.) The Social Crisis and Educational Research (London, Croom Helm), pp. 256-285.

HARgreaves, A. (1981) Contrastive rhetoric and extremist talk, in: L. BARTON \& S. WALKER (Eds.) Schools, Teachers and Thinking (Lewes, Falmer Press). 
JAMES, B. (1986) Taking gender into account: feminist and sociological issues in social research, New Zealand Sociology, 1(1), May, pp. 18-33.

LIPSEY, M.W., CORDAY, D.S. \& BERGER, D.E. (1981) Evaluation of a juvenile diversion program: using multiple lines of evidence, Evaluation Review, 5(3).

MORGan, D. (1981) Men, masculinity and the process of sociology enquiry, in: H. RoBerTs (Ed.) Doing Feminist Research (London, Routledge \& Kegan Paul).

Pollard, A. (1984) Ethnography and Social Policy for Classroom Practice, in: L. BARTon \& S. WALKER (Eds) The Social Crisis and Educational Research (London, Croom Helm), pp. 171-199.

RAMSAY, P.D.K. (1983) Fresh perspectives on the school transformation-reproduction debate: a response to Anyon from the Antipodes, Curriculum Inquiry, 13, pp. 295-320.

RAMSAY, P.D.K. (1985) Ethonographic Methods for Obtaining Data on New Zealand Schools, Working Paper No. 11, Project One in Seven (Hamilton, University of Waikato).

RosE, J. (1975) Introduction to Sociology (New York, Rand McNally).

RIST, R.C. (1984) On the application of qualitative research to the policy process: an emergent linkage, in: L. BARTON \& S. WALKer (Eds) The Social Crisis and Educational Research (London, Croom Helm), pp. 153-170.

SHIPMAN, M. (1984) Ethnography and policy, in: R. BuRgESs (Ed.) Field Methods in the Study of Education (London, Falmer Press).

SIEBER, S.D. (1973) The integration of fieldwork and survey methods, American fournal of Sociology, 78(6), pp. $1335-1339$.

SMITH, J.K. \& Heshusius, L. (1986) Closing down the conversation: the end of the quantitative-qualitative debate among educational inquiries, Educational Researcher, January, pp. 4-12.

SMYTH, J. (1989) Problematising teaching through a 'critical' perspective on clinical supervision. Paper presented to a symposium on 'Counter Hegemonic Views and Practices in Teacher Evaluation' at Annual Meeting of the American Educational Research Association, San Francisco, March 1989.

Soltis, J.F. (1984) On the nature of educational research, Educational Researcher, pp. 5-10.

SultaNA, R.G. (1987) Schooling for work in New Zealand: a qualitative study of three high schools, Unpublished DPhil dissertation, University of Waikato, Hamilton.

Trow, N. (1957) Comment on participant observation and interviewing: a comparison, Human Organisation, 16(3), pp. 33-35.

WALKER, J.C. (1986) Remanticising resistance, romanticising culture: problems in Willis's theory of cultural production, British Fournal of Sociology of Education, 7(1), pp. 59-80.

WebB, E., CAMPBell, D.T., SChwartz, R.D. \& SECHREST, L. (1966) Unobtrusive Measures (Chicago, Rand McNally).

WILlis, P. (1977) Learning to Labour: how working class kids get working class jobs (Farnborough, Saxon House).

Woods, P. (1984) Ethnography and theory construction, in: R. BuRgESs (Ed.) Field methods in the Siudy of Education: issues and problems (London, Falmer Press). 